\title{
Peroral endoscopic myotomy regains anatomical structure and improves emptying for achalasia with multiple esophageal diverticula
}

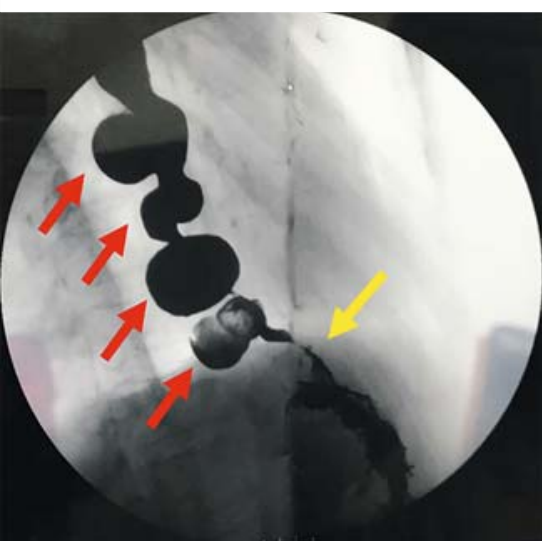

- Fig. 1 Radiographic contrast study before peroral endoscopic myotomy showing multiple diverticula (red arrows) and narrowing at the cardia (yellow arrow).

Peroral endoscopic myotomy (POEM) is a safe and effective approach for the treatment of achalasia [1]; however, the presence of esophageal diverticula significantly increases the technical difficulty. We hereby present the successful treatment using POEM for a patient with achalasia and concomitant multiple esophageal diverticula. A 74-year-old man was admitted with a history of recurrent regurgitation for 8 years and worsening dysphagia for 1 year. A radiographic contrast study showed four large esophageal diverticula and narrowing of distal esophagus that was typical of achalasia ( Fig.1). High resolution manometry suggested failure of relaxation of the lower esophageal sphincter and the absence of progressive peristalsis. Upper gastrointestinal endoscopy confirmed multiple esophageal diverticula ( $>$ Fig. 2 a) with a dilated esophagus and tight gastroesophageal junction (GEJ).

POEM was accomplished in four steps ( $\triangleright$ Video 1): mucosal entry, submucosal tunneling, myotomy and division of the septum ( $\mathbf{F i g} \mathbf{2} \mathbf{b}$ ), and mucosal closure. The procedure was accomplished in an operative time of 85 minutes. Post-pro-
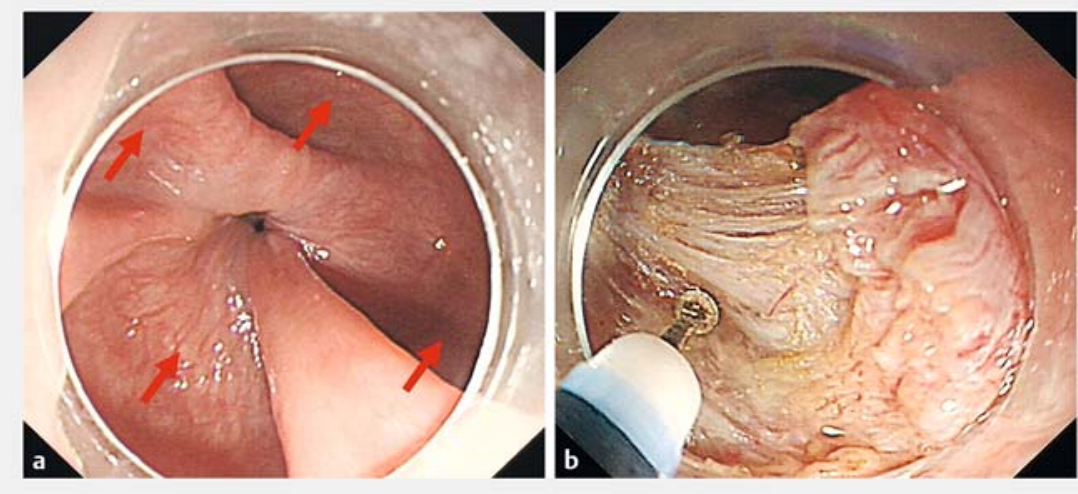

- Fig. 2 Endoscopic views showing: a the septa of the esophageal diverticula (red arrows); b septal division and myotomy being performed.

\section{Case Presentation}
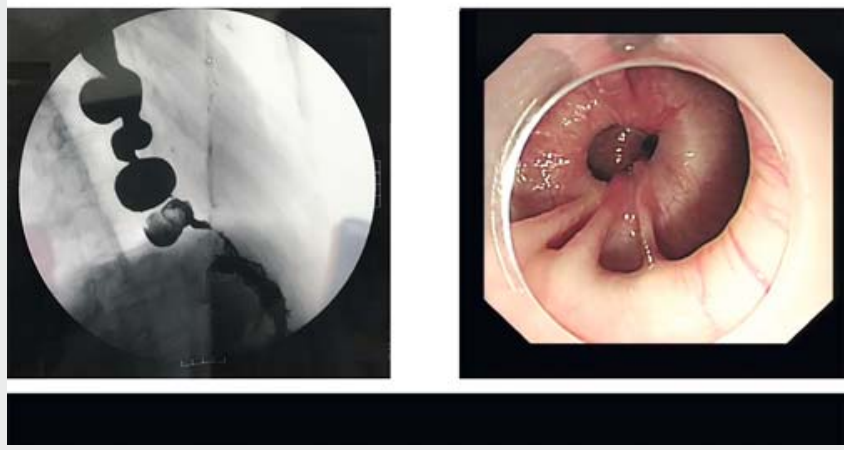

Video 1 Peroral endoscopic myotomy performed in a patient with achalasia and multiple esophageal diverticula leads to an improvement in the anatomical structure and improved emptying.

cedure, the patient developed abdominal pain and fever, which was treated with antibiotics. The patient was discharged on postoperative day 9 , by which time his symptoms were greatly relieved, and his Eckardt score had decreased from 8 to 2 at 2-month follow-up. Radiographic contrast studies on postoperative day 8 ( Fig.3) and at 2-month follow-up sug- gested relaxation of the GEJ and partial normalization of the anatomical structure of the esophagus with improved emptying.

Following myotomy of muscular fibers at the GEJ and the septa of the diverticula, the anatomical structure of the esophagus was normalized to a large extent, thereby improving peristalsis and empty- 


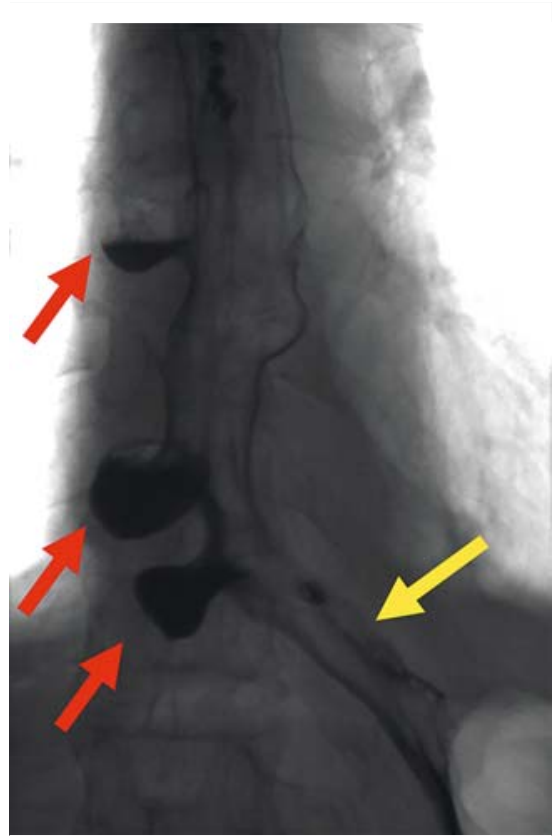

-Fig. 3 Radiographic contrast study performed on postoperative day 8 showing some improvement in the diverticula (red arrows) and of the narrowing at the cardia (yellow arrow).

ing of the esophagus. Therefore, we suggest POEM as an effective and safe alternative treatment for patients with achalasia and esophageal diverticula.

Endoscopy_UCTN_Code_TTT_1AO_2AJ

\section{Acknowledgments}

This study was supported by grants from the National Natural Science Foundation of China (81873552, 81570595, and 81670483), Major Project of Shanghai Municipal Science and Technology Committee (18ZR1406700, 16411950400, 16DZ2280900), Shanghai Rising-Star Program (19QA1401900), Shanghai Sailing Program of Shanghai Municipal Science and Technology Committee (2018YF1403700), Chen Guang Program of Shanghai Municipal Education Commission (15CG04,18CG07), and Outstanding Young Doctor Training Project of Shanghai Municipal Commission of Health and Family Planning (2017YQ026).

\section{Competing interests}

None

\section{The authors}

Xin-Yang Liu, ${ }^{1,}$, Quan-Lin Lii, ${ }^{1}$, Tai-Wei Jiao², Ming-Jun Sun ${ }^{2}$, Ping-Hong Zhou ${ }^{1}$

1 Endoscopy Center and Endoscopy Research Institute, Zhongshan Hospital, Fudan University, Shanghai, China

2 Department of Gastroenterology and Endoscopy, First Affiliated Hospital, China Medical University, Shenyang, China

${ }^{*}$ Equal first authors
Corresponding author

\section{Ping-Hong Zhou, MD}

Endoscopy Center and Endoscopy Research Institute, Zhongshan Hospital, Fudan University, Shanghai, China

Fax: +86-21-64038472

zhou.pinghong@zs-hospital.sh.cn

\section{Reference}

[1] Inoue H, Minami H, Kobayashi Y et al. Peroral endoscopic myotomy (POEM) for esophageal achalasia. Endoscopy 2010; 42: 265 271

\section{Bibliography}

DOI https://doi.org/10.1055/a-0969-1757

Published online: 25.7.2019

Endoscopy 2019; 51: E392-E393

(c) Georg Thieme Verlag KG

Stuttgart · New York

ISSN 0013-726X

\section{ENDOSCOPY E-VIDEOS}

https://eref.thieme.de/e-videos

回回 Endoscopy E-Videos is a free

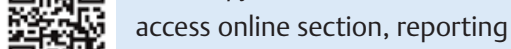
靣解: on interesting cases and new techniques in gastroenterological endoscopy. All papers include a high quality video and all contributions are freely accessible online.

This section has its own submission website at https://mc.manuscriptcentral.com/e-videos 